\title{
Clinical, surgical, and molecular prognostic factors for survival after spinal sarcoma resection
}

\author{
*Daniel M. Sciubba, MD, ${ }^{1}$ Rafael De la Garza Ramos, MD, ${ }^{1}$ C. Rory Goodwin, MD, PhD, ${ }^{1}$ \\ Nancy Abu-Bonsrah, BS, ${ }^{1}$ Ali Bydon, MD, ${ }^{1}$ Timothy F. Witham, MD, ${ }^{1}$ Chetan Bettegowda, MD, PhD, ${ }^{1}$ \\ Ziya L. Gokaslan, MD, ${ }^{2}$ and Jean-Paul Wolinsky, MD'
}

1Department of Neurosurgery, Johns Hopkins University School of Medicine, Baltimore, Maryland; and 2Department of Neurosurgery, The Warren Alpert Medical School of Brown University, Providence, Rhode Island

OBJECTIVE The goal of this study was to investigate the local recurrence rate and long-term survival after resection of spinal sarcomas.

METHODS A retrospective review of patients who underwent resection of primary or metastatic spinal sarcomas between 1997 and 2015 was performed. Tumors were classified according to the Enneking classification, and resection was categorized as Enneking appropriate (EA) if the specimen margins matched the Enneking recommendation, and as Enneking inappropriate $(E \mathrm{I})$ if they did not match the recommendation. The primary outcome measure for all tumors was overall survival; local recurrence was also an outcome measure for primary sarcomas. The association between clinical, surgical, and molecular (tumor biomarker) factors and outcomes was also investigated.

RESULTS A total of 60 patients with spinal sarcoma were included in this study (28 men and 32 women; median age 38 years). There were 52 primary (86.7\%) and 8 metastatic sarcomas (13.3\%). Thirty-nine tumors $(65.0 \%)$ were classified as high-grade, and resection was considered EA in $61.7 \%$ of all cases $(n=37)$. The local recurrence rate was 10 of $52(19.2 \%)$ for primary sarcomas; $36.8 \%$ for El resection and $9.1 \%$ for EA resection $(p=0.010)$. Twenty-eight patients $(46.7 \%)$ died during the follow-up period, and median survival was 26 months. Overall median survival was longer for patients with EA resection (undefined) compared with El resection (13 months, $p<0.001)$. After multivariate analysis, EA resection significantly decreased the hazard of local recurrence (HR $0.24,95 \% \mathrm{Cl} 0.06-0.93 ; p=0.039$ ). Age 40 years or older (HR 4.23, 95\% Cl 1.73-10.31; $p=0.002$ ), previous radiation ( $\mathrm{HR} 3.44,95 \% \mathrm{Cl} 1.37-8.63 ; p=0.008$ ), and highgrade sarcomas (HR 3.17, 95\% Cl 1.09-9.23; $p=0.034$ ) were associated with a significantly increased hazard of death, whereas EA resection was associated with a significantly decreased hazard of death $(\mathrm{HR} 0.22,95 \% \mathrm{Cl} 0.09-0.52 ; \mathrm{p}=$ $0.001)$.

CONCLUSIONS The findings in the present study suggest that EA resection may be the strongest independent prognostic factor for improved survival in patients with spinal sarcoma. Additionally, patients who underwent EA resection had lower local recurrence rates. Patients 40 years or older, those with a history of previous radiation, and those with high-grade tumors had an increased hazard of mortality in this study.

http://thejns.org/doi/abs/10.3171/2016.5.FOCUS16118

KEY WORDS spinal sarcoma; prognostic factors; Enneking appropriate; molecular; tumor biomarker; survival

$\mathrm{S}$ PINAL sarcomas represent a heterogeneous group of malignant tumors of mesenchymal origin. Although approximately 10,000 soft-tissue sarcoma cases and 2600 bone sarcoma cases are diagnosed each year in the US, ${ }^{5}$ only a small portion of these tumors are located in the spine, where they usually involve multiple vertebrae, the paraspinal musculature, and/or epidural space. ${ }^{18}$ When they do present in this location, however, the most common histological subtypes include osteosarcoma, chondrosarcoma, and Ewing sarcoma. ${ }^{17}$ Although each subtype may exhibit different biological behavior, most spinal sarcomas are best treated with resection. The combination of chemotherapy and radiotherapy is often used as a neoadjuvant or adjuvant modality. ${ }^{10}$

ABBREVIATIONS EA = Enneking appropriate; EI = Enneking inappropriate; EMA = epithelial membrane antigen; $\mathrm{PNST}=$ peripheral nerve sheath tumor.

SUBMITTED March 26, 2016. ACCEPTED May 23, 2016.

INCLUDE WHEN CITING DOI: 10.3171/2016.5.FOCUS16118.

* Drs. Sciubba and De la Garza Ramos contributed equally to this work. 
The Enneking classification system was developed as a surgical staging tool for primary nonspinal musculoskeletal tumors, ${ }^{9}$ but studies have proven its validity in primary spinal neoplasms. ${ }^{12}$ Based on tumor histological findings, anatomical extent, and the presence of metastases, the Enneking system recommends resection with negative margins for malignant tumors such as sarcoma. ${ }^{9,12,13}$ This type of resection, achieved via en bloc excision of the specimen, ${ }^{2,3,22,23}$ has been associated with decreased local recurrence and improved survival in some series, ${ }^{13,14,19}$ although others have found no difference..$^{13,18}$

The aim of this study was to report a single-institution experience with the surgical management of spinal sarcomas, and to investigate the influence of various prognostic factors and application of the Enneking classification system on local recurrence and survival.

\section{Methods}

\section{Study Population and Data}

Following institutional review board approval, a retrospective review of all neurosurgical patients undergoing surgical treatment for spinal sarcoma between 1997 and 2015 was performed. Only patients with a histologically proven sarcoma (identified by pathology notes) were included; patients with chordoma were not included in this investigation. This study represents a reanalysis of patients with spinal sarcoma treated surgically at our institution, with some patients overlapping with those in a previously published manuscript. ${ }^{14}$ Key differences between our previous report and the present one are inclusion of more patients for analysis, stratification of patients based on Enneking classification (the previous investigation did not take into account surgical margins-only en bloc vs intralesional resection), and analysis of molecular prognostic factors.

For the present study, data such as patient age, sex, history of previous tumor surgery, previous radiation, previous chemotherapy, metastatic status, tumor histological data, Enneking classification, number of vertebral levels spanned by the tumor, and biomarker positivity or negativity were retrospectively reviewed.

\section{Definitions of Classifications}

Tumors were considered primary if no other site of origin was detected during the treatment period; tumors were considered metastatic if a primary site other than the spine was identified prior to surgical treatment. Tumor histological and Enneking classification data were gathered from postoperative pathology notes, confirmed by an experienced pathologist at our institution. The Enneking classification system takes into consideration the tumor biological grade, extension, and metastasis. ${ }^{9}$ Malignant tumors are classified as Grade IA (low grade, intracompartmental, no metastasis); Grade IB (low grade, extracompartmental, no metastasis); Grade IIA (high grade, intracompartmental, no metastasis); Grade IIB (high grade, extracompartmental, no metastasis); and Grade III (high grade with metastasis). ${ }^{9}$ For the purposes of this study, tumors were dichotomized into low-grade (IA or IB) or high-grade (IIA, IIB, or III) categories. Data regarding tumor biomarker positivity were gathered from cytopathological (immunohistochemical analysis) results when available.

\section{Resection Methods}

Six different fellowship-trained spine surgeons operated on all patients in this study. Operative parameters such as tumor location and resection technique were gathered from operative and clinical notes. Tumors were classified as having undergone Enneking appropriate (EA) resection if the surgical margin matched the Enneking classification recommendation, and as Enneking inappropriate (EI) if they did not match the recommendation. ${ }^{12}$ Given that all spinal sarcomas are malignant neoplasms, the recommendation for all patients was for them to undergo en bloc resection of their tumors, with wide margins. Given that there is no universal consensus on the definition of "wide" margins in the spine, only tumors that were delivered en bloc with negative margins (the tumor did not clearly reach the edge of the specimen and no capsular violation was noted) were classified as EA; the final decision regarding margin was determined by both an experienced pathologist at our institution and the attending spine surgeon. The decision to perform an en bloc resection was made by the surgeon and patient, taking into consideration the anatomical location of the tumor, metastatic status, risk of neurovascular injury, necessity of nerve root sacrifice, overall patient functional status, and intraoperative findings. Tumors removed in a piecemeal fashion were categorized as inappropriate resections. Tumors that were delivered in a single piece but with capsular violation or tumors that reached the edge of the specimen (in the pathological review) were also categorized as inappropriate resection.

Patients were routinely followed at 3,6, and 12 months after surgery, and every 6-12 months thereafter. Follow-up periods were defined as the interval from the date of surgery to death or to the last available clinical note. Use of adjuvant chemotherapy and radiotherapy was also noted.

\section{Outcome Measures and Statistical Analysis}

The primary end points of the study were local recurrence (for primary sarcomas) and overall survival for both primary and metastatic lesions. All data were analyzed using Stata 12 SE (StataCorp LP) and GraphPad Prism 6 (GraphPad Software, Inc.). Descriptive statistics and frequencies were performed for demographic and clinical variables. Survival analysis was estimated by KaplanMeier methods, and log-rank tests were performed to compare survival between groups. Factors with a $\mathrm{p}$ value $<0.100$ following log-rank tests were then included in a multivariate Cox proportional hazards model to calculate hazard ratios and $95 \%$ confidence intervals. A p value $<$ 0.05 was considered statistically significant.

\section{Results}

\section{Patient and Tumor Features}

Sixty patients with histologically proven spinal sarcoma who underwent surgical treatment at our institution between 1997 and 2015 were identified (Table 1). The median age at surgery for all patients was 38 years (range 
TABLE 1. Characteristics of 60 patients who underwent surgical treatment of spinal sarcoma at a single institution*

\begin{tabular}{|c|c|}
\hline Variable & Value \\
\hline Total no. of patients & 60 \\
\hline Median age in yrs (range) & $38(5-82)$ \\
\hline Male sex & $28(46.7)$ \\
\hline Previous tumor surgery & $19(31.7)$ \\
\hline Previous radiation & $19(31.7)$ \\
\hline Previous chemotherapy & $23(38.3)$ \\
\hline Metastatic sarcoma & $8(13.3)$ \\
\hline \multicolumn{2}{|l|}{ Primary histological type } \\
\hline Osteosarcoma & $13(21.7)$ \\
\hline Chondrosarcoma & $12(20.0)$ \\
\hline Ewing sarcoma & 7 (11.7) \\
\hline Malignant PNST & $6(10.0)$ \\
\hline Postradiation sarcoma & $3(5.0)$ \\
\hline Undifferentiated pleomorphic sarcoma & $3(5.0)$ \\
\hline Liposarcoma & $3(5.0)$ \\
\hline Fibrosarcoma & $3(5.0)$ \\
\hline Leiomyosarcoma & $2(3.3)$ \\
\hline Synovial sarcoma & $2(3.3)$ \\
\hline Alveolar soft part sarcoma & $2(3.3)$ \\
\hline Epithelioid sarcoma & $1(1.7)$ \\
\hline Myeloid sarcoma & $1(1.7)$ \\
\hline Myxoid sarcoma & $1(1.7)$ \\
\hline Rhabdomyosarcoma & $1(1.7)$ \\
\hline \multicolumn{2}{|l|}{ Enneking classification } \\
\hline Low-grade & $21(35.0)$ \\
\hline High-grade & $39(65.0)$ \\
\hline \multicolumn{2}{|l|}{ Vertebral levels spanned by tumor } \\
\hline 1 & $13(21.7)$ \\
\hline$\geq 2$ & $47(78.3)$ \\
\hline \multicolumn{2}{|l|}{ Tumor location } \\
\hline Cervical & $11(18.3)$ \\
\hline Thoracic & $21(35.0)$ \\
\hline Lumbar & 8 (13.3) \\
\hline Sacrum & $20(33.3)$ \\
\hline \multicolumn{2}{|l|}{ Enneking resection } \\
\hline El & $23(38.3)$ \\
\hline EA & $37(61.7)$ \\
\hline Immunohistochemical evaluation & $32(53.3)$ \\
\hline Adjuvant therapy & $30(50.0)$ \\
\hline Median follow-up time in mos (range) & $18(2.5-110)$ \\
\hline
\end{tabular}

5-82 years); there were 3 pediatric patients who were 5 , 12 , and 13 years old. There were 28 males $(46.7 \%)$ and 32 females $(53.3 \%)$. Previous tumor surgery was performed in 19 patients (31.7\%), previous radiation in 19 patients (31.7\%), and previous chemotherapy in 23 cases (38.3\%). Primary sarcomas were resected in 52 patients $(86.7 \%)$ and metastatic sarcomas in $8(13.3 \%)$. The most common tumor histological type was osteosarcoma in $21.7 \%$ of cases $(n=13)$, followed by chondrosarcoma in $20.0 \%$ ( $n=$ 12), and Ewing sarcoma in $11.7 \%(\mathrm{n}=7)$ of patients. There were 39 high-grade tumors $(65.0 \%)$ and 21 low-grade tumors $(35.0 \%)$. The most common tumor location was the thoracic spine with 21 cases (35.0\%), followed by the sacrum with $20(33.3 \%)$, cervical spine with $11(18.3 \%)$, and lumbar spine with 8 (13.3\%).

\section{Tumor Resection and Enneking Appropriateness}

Thirty-seven patients $(61.7 \%)$ underwent an EA resection and 23 had an EI resection (38.3\%). An EA resection was achieved via sacrectomy in 7 patients, hemisacrectomy in 7 patients, en bloc spondylectomy in 13 patients, and via en bloc resection of posterior elements/paraspinal tissue in 10 cases. The percentage of patients with a lowgrade tumor who underwent EA resection was $66.7 \%$ versus $59.0 \%$ for high-grade lesions $(\mathrm{p}=0.559)$.

The average operative time was 515 minutes ( 8 hours and 35 minutes), the average estimated blood loss was $1733 \mathrm{ml}$, and the average length of stay was 16 days. Twenty-five patients $(41.7 \%)$ developed at least 1 perioperative complication. Wound dehiscence occurred in 8 patients (13.3\%); wound infection occurred in 7 (11.7\%); deep vein thrombosis in $6(10 \%)$; postoperative CSF leak in $5(8.3 \%)$; ileus in 4 (6.7\%); pneumonia in $4(6.7 \%)$; pulmonary embolism in 2 (3.3\%); syndrome of inappropriate antidiuretic hormone secretion in 2 (3.3\%); respiratory failure in 2 (3.3\%); and seroma, vascular injury, cardiogenic shock, sepsis, hematoma, and Clostridium difficile infection in 1 case each (1.7\% each). Among the cases of wound dehiscence (13.3\%), 5 occurred in the 41 patients with no history of radiation (12.2\%), and 3 were in the 19 patients with a history of radiation $(15.8 \%, \mathrm{p}=0.703)$.

In 32 patients $(53.3 \%)$, postoperative immunohistochemical evaluation of their tumor specimen was performed. The 6 most common biomarkers were actin, desmin, epithelial membrane antigen (EMA), keratin, S100, and synaptophysin. Distinct tumors (based on histological findings) shared several biomarkers. Of 8 patients who showed positivity for actin, there were 2 who had postradiation sarcoma, 2 had leiomyosarcoma, 2 had osteosarcoma, 1 had fibrosarcoma, and 1 had rhabdomyosarcoma. Desmin was positive in 2 patients with leiomyosarcoma, in 1 with osteosarcoma, and in 1 with undifferentiated pleomorphic sarcoma. EMA was positive in 1 patient with synovial sarcoma, in 1 with fibrosarcoma, and in 1 with osteosarcoma. Of 4 patients with keratin positivity, there was 1 case of synovial sarcoma, 1 of fibrosarcoma, 1 of osteosarcoma, and 1 of epithelioid sarcoma. Of 9 patients who showed positivity for S100, there were 4 cases of malignant peripheral nerve sheath tumor (PNST), 2 of Ewing sarcoma, 1 of osteosarcoma, 1 of chondrosarcoma, and 1 of alveolar soft part sarcoma. Last, synaptophysin was positive in 3 patients with Ewing sarcoma and in 1 with synovial sarcoma.

A total of 30 patients (50.0\%) underwent adjuvant chemotherapy and radiotherapy; 17 received adjuvant chemotherapy (28.3\%) and 22 received adjuvant radiation (36.7\%). The median follow-up period for all patients was 18 months (range 2.5-110 months); 10 months (range 


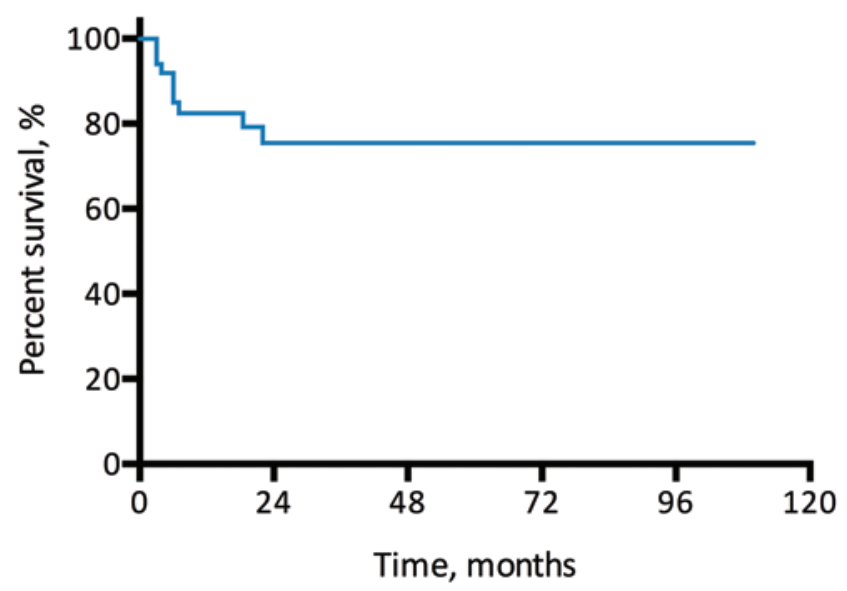

TABLE 2. Univariate analysis of factors affecting local recurrence in 52 patients with a primary sarcoma (log-rank tests)

\begin{tabular}{|c|c|c|c|}
\hline Variable & $\begin{array}{c}\text { No. of } \\
\text { Patients }\end{array}$ & $\begin{array}{c}\text { Local } \\
\text { Recurrence (\%) }\end{array}$ & $\begin{array}{c}p \\
\text { Value }\end{array}$ \\
\hline Age & & & 0.769 \\
\hline$<40$ & 27 & $7(25.9)$ & \\
\hline$\geq 40$ & 25 & $3(12.0)$ & \\
\hline Sex & & & 0.331 \\
\hline Female & 30 & $7(23.3)$ & \\
\hline Male & 22 & $3(13.6)$ & \\
\hline Previous tumor surgery & & & 0.397 \\
\hline No & 35 & $8(22.9)$ & \\
\hline Yes & 17 & $2(11.8)$ & \\
\hline Previous radiation & & & 0.687 \\
\hline No & 36 & $8(22.2)$ & \\
\hline Yes & 16 & $2(12.5)$ & \\
\hline Previous chemotherapy & & & 0.698 \\
\hline No & 25 & $6(24.0)$ & \\
\hline Yes & 17 & $4(23.5)$ & \\
\hline Histology & & & 0.170 \\
\hline Osteosarcoma & 12 & $2(16.7)$ & \\
\hline Chondrosarcoma & 12 & $0(0.0)$ & \\
\hline Malignant PNST & 6 & $3(50.0)$ & \\
\hline Ewing sarcoma & 5 & $1(20.0)$ & \\
\hline Other & 17 & $4(23.5)$ & \\
\hline Enneking classification & & & $0.027^{*}$ \\
\hline Low & 21 & $1(4.8)$ & \\
\hline High & 31 & $9(29.0)$ & \\
\hline Vertebral levels spanned by tumor & & & 0.392 \\
\hline 1 & 10 & $3(30.0)$ & \\
\hline$\geq 2$ & 42 & $7(16.7)$ & \\
\hline Actin positivity & & & 0.654 \\
\hline No & 1 & $0(0.0)$ & \\
\hline Yes & 7 & $1(14.3)$ & \\
\hline Desmin positivity & & & 0.180 \\
\hline No & 6 & $2(33.3)$ & \\
\hline Yes & 4 & $0(0.0)$ & \\
\hline EMA positivity & & & 0.479 \\
\hline No & 5 & $2(40.0)$ & \\
\hline Yes & 2 & $0(0.0)$ & \\
\hline Keratin positivity & & & 0.362 \\
\hline No & 9 & $2(22.2)$ & \\
\hline Yes & 3 & $0(0.0)$ & \\
\hline S100 positivity & & & 0.874 \\
\hline No & 9 & $2(22.2)$ & \\
\hline Yes & 9 & $2(22.2)$ & \\
\hline Synaptophysin & & & 1.00 \\
\hline No & 6 & $1(16.7)$ & \\
\hline Yes & 1 & $0(0.0)$ & \\
\hline
\end{tabular}

Twenty-eight patients (46.7\%) died during the followup period, and the median overall survival of the entire cohort was 26 months. The 12-year-old patient with re-

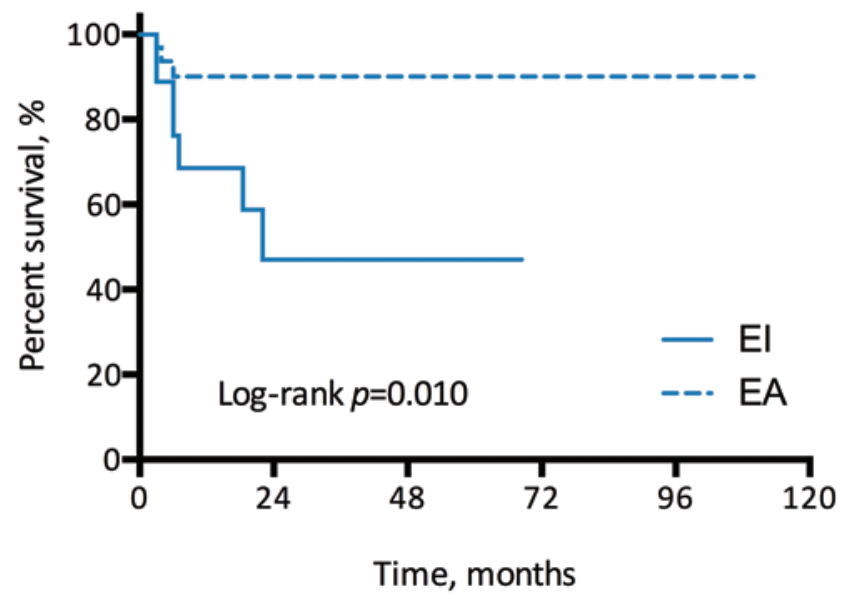

FIG. 1. Kaplan-Meier curves for recurrence-free survival for patients with primary sarcomas. Upper: The 1-, 3-, and 5-year local recurrence survival rates were $85 \%, 76 \%$, and $76 \%$, respectively. Lower: The median recurrence-free survival for patients with El resection was 22 months, and it was undefined for patients with EA resection $(p=0.010)$.

2.5-32.2 months) for patients who died during the study period and 26 months (range 2.9-110 months) for patients who did not die.

\section{Local Recurrence}

Of 52 cases of primary sarcoma, local recurrence was observed in 10 patients $(19.2 \%)$. One of these recurrences occurred in a 12-year-old pediatric patient with osteosarcoma 18.5 months after EI resection. The 1-, 3-, and 5-year local recurrence rate was $85 \%, 76 \%$, and $76 \%$ (Fig. 1 upper). The association between specific parameters and local recurrence based on the log-rank test is summarized in Table 2. The local recurrence rate was $29 \%$ for highgrade tumors and $4.8 \%$ for low-grade lesions $(\mathrm{p}=0.027)$. Patients who underwent an EI resection had a 36.8\% local recurrence rate, versus $9.1 \%$ in the EA group $(\mathrm{p}=0.010)$ (Fig. 1 lower).

\section{Survival}


» CONTINUED FROM PAGE 4

TABLE 2. Univariate analysis of factors affecting local recurrence in 52 patients with a primary sarcoma (log-rank tests)

\begin{tabular}{lccc}
\hline Variable & $\begin{array}{c}\text { No. of } \\
\text { Patients }\end{array}$ & $\begin{array}{c}\text { Local } \\
\text { Recurrence (\%) }\end{array}$ & $\begin{array}{c}\mathrm{p} \\
\text { Value }\end{array}$ \\
\hline Enneking resection & & & $0.010^{*}$ \\
\hline El & 19 & $7(36.8)$ & \\
\hline EA & 33 & $3(9.1)$ & \\
\hline Adjuvant therapy & & & 0.253 \\
\hline No & 28 & $4(14.3)$ & \\
\hline Yes & 24 & $6(25.0)$ & \\
\hline
\end{tabular}

* Included in the multivariate model.

current osteosarcoma died after rapid disease progression 18.5 months after surgery, and the other pediatric patients (the 5-year-old and 13-year-old patients) were alive at 17 and 43 months of follow-up, respectively. The 1-, 3-, and 5 -year survival rates were $72 \%, 42 \%$, and $42 \%$, respectively (Fig. 2 upper). The association of specific parameters and survival is summarized in Table 3. Using a $\mathrm{p}$ value cutoff of $<0.100$, age 40 years or older $(p=0.092)$, previous tumor surgery $(\mathrm{p}=0.077)$, previous radiation $(\mathrm{p}=$ $0.003)$, metastatic tumors $(\mathrm{p}=0.064)$, and high-grade tumors $(\mathrm{p}=0.027)$ were associated with survival. The mortality rate for EI resections was $87.3 \%$, versus $27.0 \%$ in EA resections ( $p<0.001)$ (Fig. 2 lower).

\section{Independent Prognostic Factors}

After multivariate analysis, EA resection was independently associated with a lower risk of local recurrence for primary tumors (HR $0.24,95 \%$ CI $0.06-0.93 ; \mathrm{p}=0.039$ ) (Table 4). Age 40 years or older (HR 4.23, 95\% CI 1.73$10.31 ; \mathrm{p}=0.002$ ), previous radiation (HR $3.44,95 \% \mathrm{CI}$ $1.37-8.63 ; \mathrm{p}=0.008$ ), and high-grade tumors (HR 3.17, $95 \%$ CI $1.09-9.23$; $\mathrm{p}=0.034$ ) were independently associated with a significantly increased hazard of death, whereas EA resection was associated with a significantly decreased hazard of death (HR $0.22,95 \%$ CI $0.09-0.52$; $\mathrm{p}=0.001$ ).

\section{Discussion}

Spinal sarcomas are uncommon malignant tumors. Given that they may arise from cancellous bone, cartilage, fat, muscle, vascular, or hematopoietic tissue, more than 50 histological subtypes have been described.$^{8}$ Removal of these lesions with negative margins via an EA resection has been shown to improve recurrence-free and overall survival in some studies. ${ }^{1,4,12,14}$ Additionally, newer studies have suggested that molecular factors may influence survival in patients with tumors such as malignant PNST and chordoma, ${ }^{6,24}$ but these factors' association with survival in other spinal sarcomas remains unknown.

In this study, we report a cohort of 60 patients who underwent surgical treatment for spinal sarcomas at a single institution. The local recurrence rate for primary lesions was $19.2 \%$ and the mortality rate for all tumors was $46.7 \%$. Recurrences were significantly lower for patients who un-

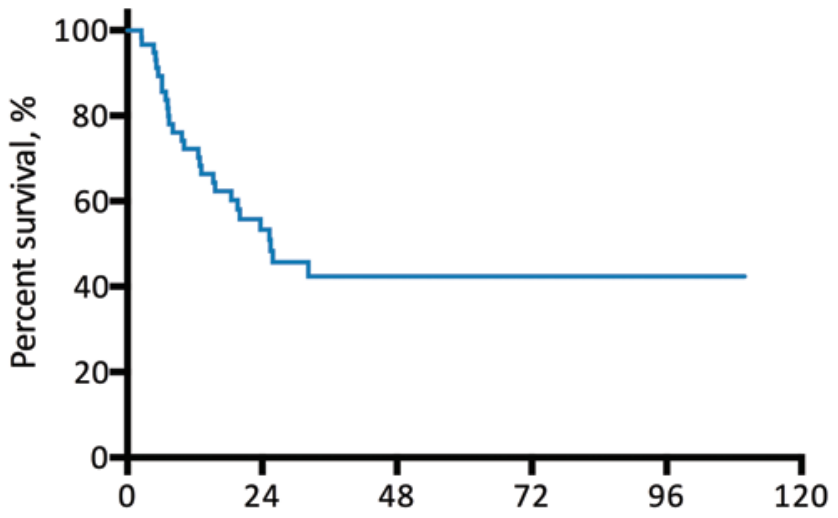

Time, months

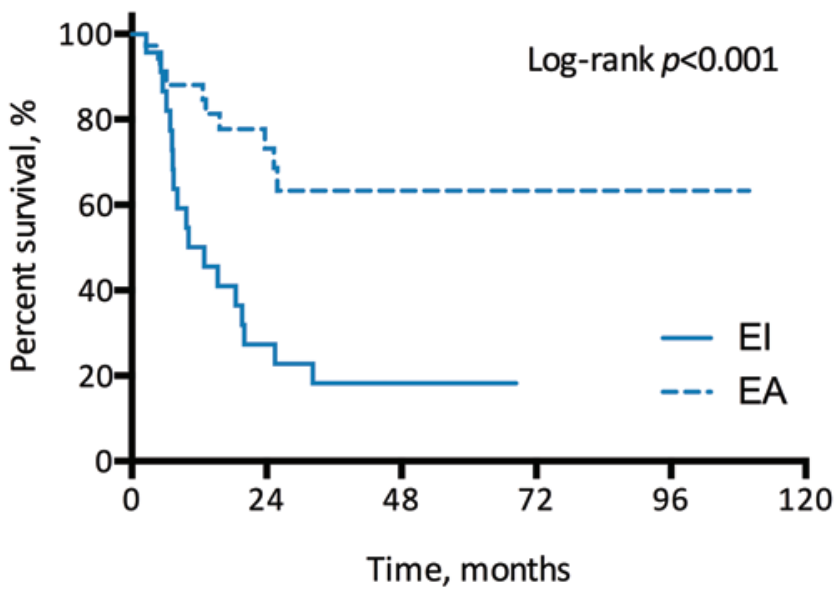

FIG. 2. Kaplan-Meier curves for overall survival for all patients with sarcomas. Upper: The 1-, 3-, and 5-year survival rates were $72 \%, 42 \%$, and $42 \%$, respectively. Lower: The median overall survival for patients with El resection was 13 months, and it was undefined for patients with EA resection $(p<0.001)$.

derwent an EA resection (9.1\%) compared with patients who underwent an EI resection (36.8\%, $\mathrm{p}=0.010$ ); mortality was also lower for the EA (27.0\%) compared with the EI group (87.3\%, $\mathrm{p}<0.001)$. More importantly, EA resection was independently associated with lower risk of local recurrence and improved survival after controlling for patient characteristics, previous treatment, metastatic status, and tumor grade. On the other hand, patients 40 years or older, patients with history of radiation, and patients with a high-grade tumor had a higher risk of death.

The advantage of en bloc over intralesional resection of spinal sarcomas has been previously described in the literature. In the year 2000, Boriani et al. reported their experience after resection of chondrosarcoma in 22 patients $-100 \%$ of patients $(10 / 10)$ treated with curettage had local recurrence, compared with $25 \%$ (3/12) of patients treated with en bloc resection. ${ }^{4}$ Additionally, $80 \%$ of patients treated with intralesional resection died at a mean of 36 months. In a similar study, also by Boriani et al., 17 patients were treated for Ewing sarcoma by intralesional resection $(n=7)$ or en bloc resection $(n=10) .{ }^{1}$ All patients in that study who underwent intralesional or en bloc resection with contaminated margins died of the disease 10-63 
TABLE 3. Univariate analysis of factors affecting overall survival in 60 patients with primary and metastatic sarcoma (log-rank tests)

\begin{tabular}{|c|c|c|c|}
\hline Variable & $\begin{array}{c}\text { No. of } \\
\text { Patients }\end{array}$ & $\begin{array}{l}\text { Deaths } \\
(\%)\end{array}$ & $p$ Value \\
\hline Age & & & $0.092^{*}$ \\
\hline$<40$ & 32 & $14(43.8)$ & \\
\hline$\geq 40$ & 28 & $14(50.0)$ & \\
\hline Sex & & & 0.158 \\
\hline Female & 32 & $17(53.1)$ & \\
\hline Male & 28 & $11(39.3)$ & \\
\hline Previous tumor surgery & & & $0.077^{*}$ \\
\hline No & 41 & $16(39.0)$ & \\
\hline Yes & 19 & $12(63.2)$ & \\
\hline Previous radiation & & & $0.003^{*}$ \\
\hline No & 41 & $16(39.0)$ & \\
\hline Yes & 19 & $12(63.2)$ & \\
\hline Previous chemotherapy & & & 0.925 \\
\hline No & 37 & $17(46.0)$ & \\
\hline Yes & 23 & $11(47.8)$ & \\
\hline Metastatic tumor & & & $0.064^{*}$ \\
\hline No & 52 & $21(40.4)$ & \\
\hline Yes & 8 & $7(87.5)$ & \\
\hline Histology & & & 0.673 \\
\hline Osteosarcoma & 13 & $6(46.2)$ & \\
\hline Chondrosarcoma & 12 & $3(25.0)$ & \\
\hline Malignant PNST & 6 & $4(66.7)$ & \\
\hline Ewing sarcoma & 7 & $2(28.6)$ & \\
\hline Other & 22 & $13(59.1)$ & \\
\hline Enneking classification & & & $0.027^{*}$ \\
\hline Low & 21 & $5(23.8)$ & \\
\hline High & 39 & $23(59.0)$ & \\
\hline Vertebral levels spanned by tumor & & & 0.425 \\
\hline 1 & 13 & $8(61.5)$ & \\
\hline$\geq 2$ & 47 & $20(42.6)$ & \\
\hline Actin positivity & & & 0.835 \\
\hline No & 1 & $1(100.0)$ & \\
\hline Yes & 8 & $4(50.0)$ & \\
\hline Desmin positivity & & & 0.632 \\
\hline No & 8 & $4(50.0)$ & \\
\hline Yes & 4 & $2(50.0)$ & \\
\hline EMA positivity & & & 0.196 \\
\hline No & 5 & $3(60.0)$ & \\
\hline Yes & 3 & $3(100.0)$ & \\
\hline Keratin positivity & & & 0.676 \\
\hline No & 12 & $5(41.7)$ & \\
\hline Yes & 4 & $3(75.0)$ & \\
\hline S100 positivity & & & 0.584 \\
\hline No & 11 & $6(54.6)$ & \\
\hline Yes & 9 & $4(44.4)$ & \\
\hline
\end{tabular}

» CONTINUED FROM PREVIOUS COLUMN

TABLE 3. Univariate analysis of factors affecting overall survival in 60 patients with primary and metastatic sarcoma (log-rank tests)

\begin{tabular}{lccc}
\hline \multicolumn{1}{c}{ Variable } & $\begin{array}{c}\text { No. of } \\
\text { Patients }\end{array}$ & $\begin{array}{c}\text { Deaths } \\
(\%)\end{array}$ & p Value \\
\hline Synaptophysin & & & 0.394 \\
\hline No & 6 & $3(50.0)$ & \\
\hline Yes & 4 & $3(75.0)$ & \\
\hline Enneking resection & & & $<0.001^{*}$ \\
\hline El & 23 & $18(78.3)$ & \\
\hline EA & 37 & $10(27.0)$ & \\
\hline Adjuvant therapy & & & 0.398 \\
\hline$\quad$ No & 30 & $12(40.0)$ & \\
\hline Yes & 30 & $16(53.3)$ & \\
\hline * Included in the multivariate model. & & &
\end{tabular}

* Included in the multivariate model.

months after treatment; only 1 patient $(1 / 6)$ who underwent en bloc resection with negative margins had disease recurrence, and died 29 months after surgery. Likewise, we previously reported a cohort of 25 patients with spinal sarcoma who underwent surgery at our institution between 2002 and 2012, finding a survival advantage of en bloc versus intralesional resection $(\mathrm{p}=0.049) .{ }^{14}$

In contrast to these previous findings, Rao et al. reported their experience with 88 patients treated for primary and metastatic spinal sarcomas, finding no significant differences in survival or local recurrence rates between en bloc and intralesional resection. ${ }^{18}$ However, their study only included 12 patients (11\%) with en bloc resection, which may have resulted in an underpowered analysis. Fisher et al. recently reported outcomes in 104 patients who underwent EA or EI resection for spinal chondrosarcoma. Although the mortality rate for patients with EA resections was $25 \%$ and it was $39 \%$ for patients with EI resections, there was no statistically significant difference according to the log-rank test $(\mathrm{p}=0.529)$. The EA resections resulted in a $21 \%$ local recurrence rate and the EI resections resulted in a $48 \%$ recurrence rate (univariate analysis, $\mathrm{p}=0.010$ ); however, contrary to our findings, EA resection did not reach statistical significance for improved recurrence-free survival after multivariate analysis in that study $(\mathrm{p}=0.052) .{ }^{13}$

Older patients (40 years or older) were found to have higher mortality rates in the present study. Commensurate with this finding, Fisher et al. also found that increasing age at surgery independently increased the risk of death (HR 1.16) in their study of vertebral column chondrosarcomas..$^{13}$ Spinal sarcomas in children are less common than in adults, and in our study only $3 / 60$ patients $(5 \%)$ were younger than 18 years of age. However, given that certain tumors such as Ewing's are mostly seen in the pediatric population, pediatric patients may also present with spinal sarcomas. Diagnosis of these lesions in children (particularly very young ones) may be somewhat more challenging than in adults, given that neurological abnormalities are oftentimes subtler and symptoms may include irritability, poor developmental progression, pseudoparesis, and oth- 
TABLE 4. Multivariate analysis of factors associated with local recurrence (primary tumors) and overall survival (all tumors)

\begin{tabular}{llll}
\hline \multicolumn{1}{c}{ Factor } & $\mathrm{HR}$ & $95 \% \mathrm{Cl}$ & $\mathrm{p}$ Value \\
\hline Local recurrence & & & \\
\hline High-grade tumor & 6.06 & $0.76-48.2$ & 0.088 \\
\hline EA resection & 0.24 & $0.06-0.93$ & $0.039^{*}$ \\
\hline Overall survival & & & \\
\hline Age $\geq 40$ & 4.23 & $1.73-10.31$ & $0.002^{*}$ \\
\hline Previous tumor surgery & 1.11 & $0.45-2.70$ & 0.812 \\
\hline Previous radiation & 3.44 & $1.37-8.63$ & $0.008^{*}$ \\
\hline Metastatic tumor & 1.45 & $0.57-3.68$ & 0.432 \\
\hline High-grade tumor & 3.17 & $1.09-9.23$ & $0.034^{*}$ \\
\hline EA resection & 0.22 & $0.09-0.52$ & $0.001^{*}$ \\
\hline
\end{tabular}

* Indicates statistical significance.

ers. ${ }^{15}$ The same principles of treatment (use of neoadjuvant or adjuvant chemoradiotherapy and resection) are applied as in the adult population, but excessive blood loss is more critical in children and careful preoperative planning is encouraged. Additionally, consideration of the long-term implications of spinal reconstruction in children should be considered (such as need for future revision surgery, adjacent-segment disease, and so on).

Interestingly, previous radiation was also associated with a higher mortality risk in our study. Studies have suggested that ionizing radiation may in fact increase cell tumorigenicity, ${ }^{16}$ particularly in cases in which the tumor is not completely removed and radiation is used as adjuvant therapy (31.7\% of patients in our study had previous resection and $31.7 \%$ had previous radiation). Seaberg et al. suggested that patients with a history of exposure to radiation (therapeutic, occupational, diagnostic, or environmental) before undergoing surgical treatment for thyroid cancer have more aggressive disease and worse clinical outcomes than patients without previous radiation exposure. ${ }^{20}$ In that study, patients with a history of radiation were more likely to have multifocal disease, extrathyroid extension, Stage IV disease, and distant metastases. Despite these findings, the heterogeneous population in our study may have confounded this analysis, given that radiation treatment is part of the adjuvant therapy of certain spinal sarcomas.

A higher sarcoma grade (specifically Grade III sarcomas) was associated with decreased recurrence-free survival on univariate analysis and with decreased overall survival on multivariate analysis. The local recurrence rate was $29.0 \%$ for high-grade tumors and $4.8 \%$ for low-grade lesions $(p=0.027)$; the mortality rate was $59.0 \%$ for highgrade tumors and $23.8 \%$ for low-grade tumors $(\mathrm{p}=0.027)$. Higher-grade tumors are poorly differentiated, and have high mitotic counts and necrosis, all indicators of a more aggressive nature. In fact, Rao et al.'s study of 80 patients who underwent surgery for primary or metastatic sarcoma found that the only consistent independent predictor of shorter survival was a high-grade tumor, for both primary and metastatic lesions (median survival of 14 months for a high-grade tumor and 33.3 months for a low-grade tumor $[\mathrm{p}=0.002]) .^{18}$
Biomarker identification via immunohistochemical analysis for assessment of prognostic factors has gained popularity in the last decades. ${ }^{6,11,21,24}$ Wang et al. demonstrated that patients with S100-negative malignant PNSTs had significantly higher local recurrence rates and lower overall survival compared with those with S100-positive tumors. ${ }^{24}$ In our study, an attempt to identify relevant biomarkers was made, but no significant associations were found. Given that this was performed in a retrospective fashion and that a relatively low proportion of patients had lesions that underwent immunohistochemical analysis, further research is encouraged before definitive conclusions can be made. In fact, research has shown that molecular profiling may be of great value for certain cancers, even more than traditional classification based on histological findings. ${ }^{7}$ In the future, it may be possible that targeted therapies will be directed at sarcomas based not only on the gross appearance of the tumor, but on the positivity or negativity of specific biomarkers.

Although technically demanding and producing a fair amount of morbidity, EA resections of spinal tumors, when feasible, may provide a longer recurrence-free and overall survival. However, performing resection with negative margins is not always feasible. Large or infiltrative lesions may require multiple procedures before complete resection can be achieved, or they may require capsular violation and thus contamination (Fig. 3). Tumors in proximity to the spinal cord or nerve roots may not always be removed en bloc, given that sacrifice of these structures may be either fatal or severely disabling for the patient. It is important to consider the tumor characteristics (histological findings and grade), location, metastatic status, patient's functional status, and risks and benefits before establishing a surgical plan. Although an EA resection with negative margins may be the ultimate goal for treatment, this feat is not always possible, and adjuvant therapy may be necessary.

Although this study reports a large cohort of patients treated for spinal sarcomas at a single institution (cases were less subject to treatment variation and thus bias), it has several limitations. The heterogeneity of histological subtypes, the inclusion of both primary and metastatic lesions, and the inclusion of patients with a history of treatment may have confounded the results. The biological behavior of chondrosarcoma, osteosarcoma, Ewing sarcoma, and other sarcomas is different, but to power the study, the tumors were grouped together into low and high grades. Additionally, tumors in only a small percentage of patients underwent immunohistochemical analysis, which may have underpowered the study. Nonetheless, all of these factors were controlled for in the multivariate model for prognostic factor identification. Future prospective multicenter collaborations with a uniform treatment strategy will allow for larger patient cohorts as well as identification of valuable prognostic variables for survival.

\section{Conclusions}

Primary and metastatic sarcomas of the spine are uncommon tumors. The findings in the present study suggest that EA resections may significantly reduce the local recurrence rate for primary sarcomas and the overall 

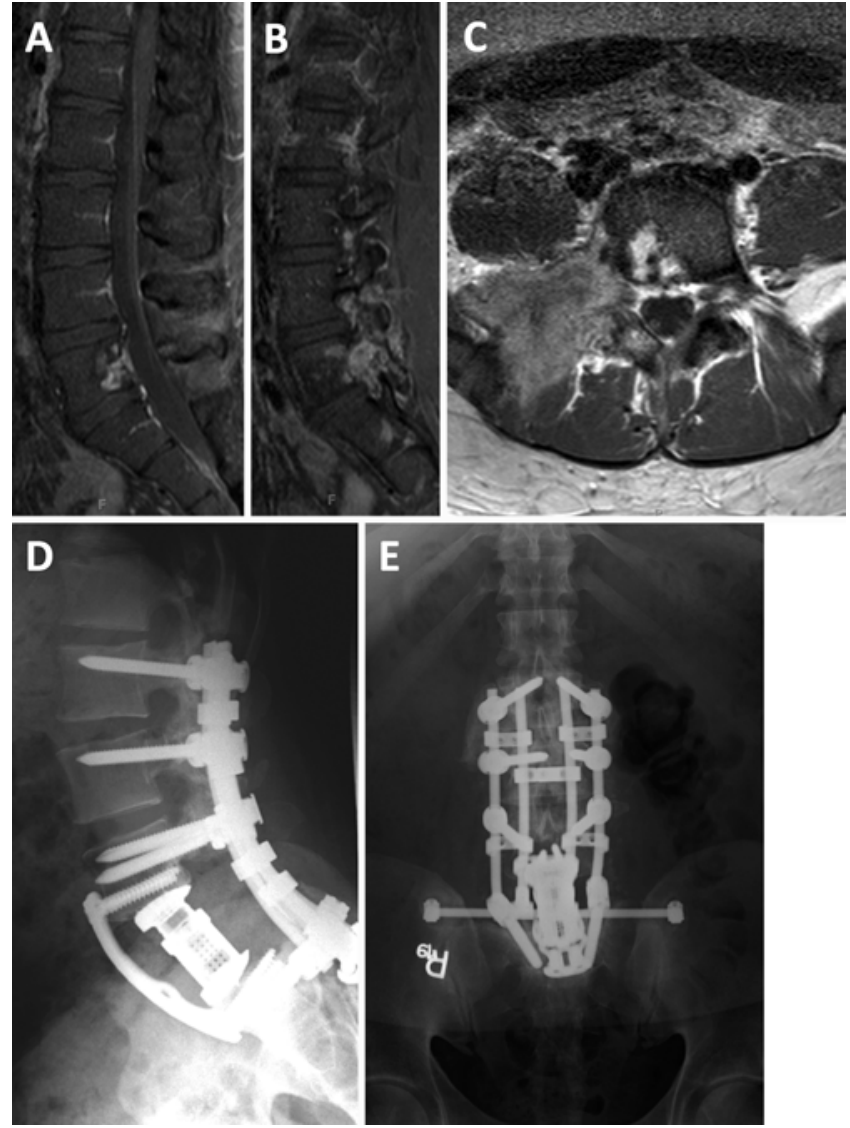

FIG. 3. A 24-year-old man presented with a several-month history of persistent low-back pain and right-sided radiculopathy. A-C: Preoperative MRI revealed a tumor involving the L- 5 vertebral body with extension into the right intervertebral foramen, posterior elements, and paraspinal soft tissue. A high-grade synovial sarcoma (EMA negative) was diagnosed and the patient received 3 cycles of mesna, doxorubicin, and ifosfamide. Afterward, a 2-stage L-5 spondylectomy was performed, but the tumor could not be removed with negative margins due to extensive paraspinal soft-tissue infiltration (El resection). D and E: Postoperative radiographs. The patient underwent lumbosacral reconstruction from $\mathrm{L}-2$ to pelvis. Postoperatively, he received radiation therapy (total dose 5940 cGy to the surgical bed), but had a local recurrence 22 months after surgery. Unfortunately, he died of disease progression 32 months after his index operation at the Department of Neurosurgery, The Johns Hopkins Hospital.

survival for both primary and metastatic lesions. However, older patients, patients with a history of radiation, and patients with a high-grade tumor may have a higher risk of death. Future investigation into clinical, surgical, and molecular prognostic factors may help in determining the best patient-specific therapy.

\section{References}

1. Boriani S, Amendola L, Corghi A, Cappuccio M, Bandiera S, Ferrari S, et al: Ewing's sarcoma of the mobile spine. Eur Rev Med Pharmacol Sci 15:831-839, 2011

2. Boriani S, Bandiera S, Biagini R, Bacchini P, Boriani L, Cappuccio M, et al: Chordoma of the mobile spine: fifty years of experience. Spine (Phila Pa 1976) 31:493-503, 2006

3. Boriani S, Biagini R, De Iure F, Bertoni F, Malaguti MC, Di
Fiore M, et al: En bloc resections of bone tumors of the thoracolumbar spine. A preliminary report on 29 patients. Spine (Phila Pa 1976) 21:1927-1931, 1996

4. Boriani S, De Iure F, Bandiera S, Campanacci L, Biagini R, Di Fiore M, et al: Chondrosarcoma of the mobile spine: report on 22 cases. Spine (Phila Pa 1976) 25:804-812, 2000

5. Burningham Z, Hashibe M, Spector L, Schiffman JD: The epidemiology of sarcoma. Clin Sarcoma Res 2:14, 2012

6. Chen K, Mo J, Zhou M, Wang G, Wu G, Chen H, et al: Expression of PTEN and mTOR in sacral chordoma and association with poor prognosis. Med Oncol 31:886, 2014

7. Cross D, Burmester JK: The promise of molecular profiling for cancer identification and treatment. Clin Med Res 2:147-150, 2004

8. Ducimetière F, Lurkin A, Ranchère-Vince D, Decouvelaere $\mathrm{AV}$, Péoc'h M, Istier L, et al: Incidence of sarcoma histotypes and molecular subtypes in a prospective epidemiological study with central pathology review and molecular testing. PLoS One 6:e20294, 2011

9. Enneking WF, Spanier SS, Goodman MA: A system for the surgical staging of musculoskeletal sarcoma. Clin Orthop Relat Res (153): 106-120, 1980

10. Enneking WF, Spanier SS, Goodman MA: A system for the surgical staging of musculoskeletal sarcoma. 1980. Clin Orthop Relat Res (415):4-18, 2003

11. Fan Q, Yang J, Wang G: Clinical and molecular prognostic predictors of malignant peripheral nerve sheath tumor. Clin Transl Oncol 16:191-199, 2014

12. Fisher CG, Saravanja DD, Dvorak MF, Rampersaud YR, Clarkson PW, Hurlbert J, et al: Surgical management of primary bone tumors of the spine: validation of an approach to enhance cure and reduce local recurrence. Spine (Phila Pa 1976) 36:830-836, 2011

13. Fisher CG, Versteeg AL, Dea N, Boriani S, Varga PP, Dekutoski MB, et al: Surgical management of spinal chondrosarcomas. Spine (Phila Pa 1976) 41:678-685, 2016

14. Groves ML, Zadnik PL, Kaloostian P, Sui J, Goodwin CR, Wolinsky JP, et al: Epidemiologic, functional, and oncologic outcome analysis of spinal sarcomas treated surgically at a single institution over 10 years. Spine J 15:110-114, 2015

15. Kim HJ, McLawhorn AS, Goldstein MJ, Boland PJ: Malignant osseous tumors of the pediatric spine. J Am Acad Orthop Surg 20:646-656, 2012

16. Lagadec C, Vlashi E, Della Donna L, Dekmezian C, Pajonk F: Radiation-induced reprogramming of breast cancer cells. Stem Cells 30:833-844, 2012

17. Ozturk AK, Gokaslan ZL, Wolinsky JP: Surgical treatment of sarcomas of the spine. Curr Treat Options Oncol 15:482-492, 2014

18. Rao G, Suki D, Chakrabarti I, Feiz-Erfan I, Mody MG, McCutcheon IE, et al: Surgical management of primary and metastatic sarcoma of the mobile spine. J Neurosurg Spine 9:120-128, 2008

19. Sciubba DM, Okuno SH, Dekutoski MB, Gokaslan ZL: Ewing and osteogenic sarcoma: evidence for multidisciplinary management. Spine (Phila Pa 1976) 34 (22 Suppl):S58S68, 2009

20. Seaberg RM, Eski S, Freeman JL: Influence of previous radiation exposure on pathologic features and clinical outcome in patients with thyroid cancer. Arch Otolaryngol Head Neck Surg 135:355-359, 2009

21. Thakkar JP, Dolecek TA, Horbinski C, Ostrom QT, Lightner DD, Barnholtz-Sloan JS, et al: Epidemiologic and molecular prognostic review of glioblastoma. Cancer Epidemiol Biomarkers Prev 23:1985-1996, 2014

22. Tomita K, Kawahara N, Baba H, Tsuchiya H, Nagata S, Toribatake Y: Total en bloc spondylectomy for solitary spinal metastases. Int Orthop 18:291-298, 1994

23. Tomita K, Kawahara N, Kobayashi T, Yoshida A, Murakami 
H, Akamaru T: Surgical strategy for spinal metastases. Spine (Phila Pa 1976) 26:298-306, 2001

24. Wang T, Yin H, Han S, Yang X, Wang J, Huang Q, et al: Malignant peripheral nerve sheath tumor (MPNST) in the spine: a retrospective analysis of clinical and molecular prognostic factors. J Neurooncol 122:349-355, 2015

\section{Disclosures}

Dr. Sciubba is a consultant for Medtronic, Inc., Globus, DepuySynthes, and Orthofix. Dr. Witham oversaw and received support for a non-study-related clinical or research effort from Eli Lilly and Co. and from The Gordon and Marilyn Macklin Foundation. C. Rory Goodwin is a United Negro College Fund Merck Postdoctoral Fellow and has received an award from the Burroughs Wellcome Fund and the Johns Hopkins Neurosurgery Pain Research Institute.

\section{Author Contributions}

Conception and design: Sciubba, De la Garza Ramos. Acquisition of data: De la Garza Ramos, Goodwin, Abu-Bonsrah, Bydon, Witham, Bettegowda, Gokaslan, Wolinsky. Analysis and interpretation of data: Sciubba, De la Garza Ramos, Goodwin, Abu-Bonsrah. Drafting the article: all authors. Critically revising the article: Sciubba, De la Garza Ramos, Witham, Gokaslan, Wolinsky. Reviewed submitted version of manuscript: Sciubba, De la Garza Ramos. Approved the final version of the manuscript on behalf of all authors: Sciubba. Statistical analysis: De la Garza Ramos. Administrative/technical/material support: Study supervision: Sciubba, Bydon, Bettegowda, Gokaslan, Wolinsky.

\section{Correspondence}

Daniel M. Sciubba, Department of Neurosurgery, The Johns Hopkins Hospital, 600 North Wolfe St., Meyer 7-185, Baltimore, MD 21287.email: dsciubb1@jhmi.edu. 